\title{
JUSTIÇA DE TRANSIÇÃO: REFLEXÕES SOBRE A IMPRESCINDIBILIDADE DA PERSECUÇÃO PENAL NO CASO BRASILEIRO
}

\author{
Transitional justice: reflections on indispensability \\ of prosecution, the case of Brazil
}

\section{Eugenius Costa Lopes da Cruz}

Pós-graduado em direito público pela Universidade Gama Filho. Mestrando em direito pela Unesa, onde realiza trabalho de pesquisa e cooperação junto à coordenação acadêmica. Integrante do Grupo de Pesquisas novas perspectivas em jurisdição constitucional (Unesa). Bolsista de estudos pela Capes. Advogado.

Recebido em: 27.07.2012

Aprovado em: 31.08.2012

ÁreA do Direito: Constitucional; Penal; Internacional

Resumo: Cuida o presente trabalho da análise do contexto social em que paises que vivenciaram periodos totalitários, após restauração de um ambiente democrático, carecem de mecanismos destinados à consolidação do regime enunciado por suas Cartas Políticas cunhadas sob nova inspiração jurídico-política. Diante do legado autoritário que se põe como herança a esse novo Estado, surge a justiça de transição como mecanismo apto a promover a transformação social que tem por objetivo a superação dos traumas que the foram impostos, buscando igualmente a consolidação dos direitos humanos. 0 texto considera ainda a problemática da falta de cultura democrática no Brasil e analisará se o mecanismo da persecução penal se mostra indispensável para a consolidação desse déficit.

\begin{abstract}
This article brings out the analysis of societies in countries that had been through tyranny regimes of exception and, after the establishment of a democratic regime, still depends on mechanisms in order to affirm democracy according to the new constitution. Given the authoritarian legacy inherited by the new regime, arises the transitional justice as a mechanism able to promote a process of social transformation with the goal of overcoming that social trauma and consolidate human rights as a whole.

Considering the lack of democratic culture in Brazil it will be analyzed if criminal prosecution is a mechanism able to face this issue.
\end{abstract}


Palavras-chave: Justiça de transição - Direitos humanos - Persecução penal.
KeYwords: Transitional justice - Human rights Criminal prosecution.

SumÁRIO: 1. Introdução - 2. Construção e evolução do conceito de justiça de transição - 3. Reflexões acerca dos limites do debate penal no cenário brasileiro: 3.1 Breve análise das anistias; 3.2 Análise crítica do argumento da prescrição - 4. Reflexões sobre a consolidação de um pensamento democrático - 5. Conclusão - 6. Referências.

\section{INTRODUÇÃO}

Ao longo das últimas décadas, o mundo atravessa uma onda de movimentos de liberdade em prol da consolidação de regimes políticos democráticos que carregam o compromisso e o encorajamento de promoverem uma transformação social, que se opera a partir da racionalidade dos direitos humanos. Por conseguinte, as bandeiras dos direitos fundamentais são hasteadas como mecanismos propulsores de concretização dos novos vetores democráticos que buscam a superação do legado de práticas de violência institucionalizada utilizadas por lideranças arbitrárias. Esta concepção é fruto do movimento de internacionalização dos direitos humanos que surge, no pós-guerra, como resposta à ruptura com o paradigma do direito das gentes, exteriorizada pela negação à condição humana aos opositores dos regimes autoritários.

No cenário brasileiro, após mais de duas décadas da restauração do regime democrático, a justiça de transição é um tema que ganha cada vez mais espaço na sociedade, através da divulgação de matérias na mídia ${ }^{1}$ e por meio dos discursos políticos. ${ }^{2}$

Como se nota, em razão da matéria versar sobre as feridas causadas no tecido social pelo regime antecedente, por vezes os debates ganham um conteúdo

1. ÉвоLI, Evandro. Deputados criam comissão da verdade paralela: Insatisfeitos com a lentidão do governo, parlamentares começam a ouvir testemunhas de crimes cometidos durante a ditadura militar. O Globo, Cad. 1, Rio de Janeiro, 04.04.2012, p. 11.

2. Como manchete da primeira página do jornal, Dilma afirma que "a busca da verdade agora é decisão de Estado". Ainda, noticiou-se que, no dia 16.05.2012, a Presidente Dilma Roussef instalou a Comissão da Verdade, criada para apurar as violações de direitos humanos no período entre 1946 e 1988. Destacou a Chefe de Estado que a iniciativa é um esforço do Estado para revelar a história recente do país, ressaltando que a palavra verdade é o contrário da palavra esquecimento e que o projeto não abriga ressentimento, ódio, nem perdão. O Globo, Rio de Janeiro, 17.05.2012, p. 1. 
acalorado, carregado de emoção e idealismo. Na questão penal, há uma grande maioria que costuma de antemão assumir um posicionamento em seus discursos sob o encantamento da retórica de que as referidas condutas praticadas pelos agentes do regime político antecedente são crimes contra a humanidade e, desta forma, são imprescritíveis e não podem ser anistiadas. É bem verdade que há uma verdadeira necessidade de prestação de contas com o passado, como forma de viabilizar a pacificação da sociedade, o que permite a sua evolução sem a constante recordação das feridas abertas no passado. ${ }^{3} \mathrm{O}$ tema ganhou maior relevância, a partir do momento em que a aludida questão conquistou espaço no âmbito internacional, a exemplo do ocorrido na condenação do estado brasileiro perante a Corte Interamericana de Direitos Humanos no caso Gomes Lund e outros versus Brasil. ${ }^{4}$

O que se pretende, ao longo do desenvolvimento do presente trabalho, é marcar os contornos do debate e as complexidades que envolvem o tema. É preciso, antes de tudo, delimitar a ordem do discurso a respeito da proteção e promoção do direito das gentes, uma vez que, se por um lado há uma onda de busca pela responsabilização das violações aos direitos humanos, por outro, esses mesmos direitos humanos representam um arsenal de contenção do poder punitivo no âmbito interno dos estados democráticos. Daí a complexidade do problema diante de uma tendência de fala, no mínimo, preocupante.

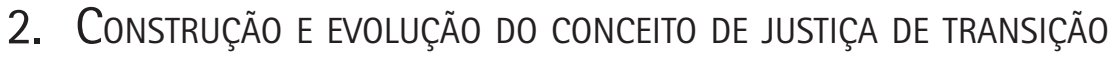

A expressão justiça de transição (transitional justice) tem sido cada vez mais utilizada quando se cuida da democratização de países que recentemente superaram um regime antidemocrático. Em outras palavras, é uma concepção daquilo que amplamente se entende como justiça, associada a períodos de transição política (de um governo repressor para um regime democrático). ${ }^{5}$

3. Tavares, André Ramos; Agra, Walber de Moura. Justiça reparadora no Brasil. In: SoARES, Inês Virgínia Prado; KISHI, Sandra Akemi Shimada (coords.). Memória e verdade: A justiça de transição no Estado Democrático brasileiro. Belo Horizonte: Fórum, 2009. p. 69-91.

4. OEA. Corte IDH. Caso Gomes Lund y otros (Guerrilha do Araguaia) vs. Brasil. Disponível em: [www.corteidh.or.cr/]. Acesso em: 13.06.2012.

5. "In prior work, I have defined transitional justice as that conception of justice associated with periods of political change". Teitel, Ruti. The law and politics of contemporary transitional justice. Social Science Research Network. New York Law School's website. Disponível em: [http://ssrn.com/abstract=943069]. Acesso em: 20.11.2011. 
Popularizada como conceito acadêmico no início dos anos noventa, principalmente relacionada ao colapso do regime do apartheid na África do Sul, a dicção ganhou força em uma variedade de contextos políticos mundo afora, incluindo os casos de conflitos armados em Ruanda, Iugoslávia, Camboja e Serra Leoa. ${ }^{6}$

Por conseguinte, a justiça reparadora, de transição ou transicional ${ }^{7}$ trata da temática voltada para o projeto político através do qual as sociedades lidam com o legado de violações aos direitos humanos, com o objetivo de assegurar tempos futuros de paz, justiça e proteção aos direitos humanos. Essa questão abrange um conjunto de estratégias judiciais e não judiciais, que normalmente envolvem o processo e julgamento pelos desvios perpetrados pelos atores políticos do regime anterior, estabelecimento de comissões de verdade, programas de reparação às vítimas e familiares pelos abusos praticados pelo governo precedente, além da previsão de reformas às instituições ${ }^{8}$ com histórico de práticas de excesso, geralmente associadas às forças armadas ou policiais, no reforço à recuperação da confiabilidade às instituições formais e na restauração do rule of law.

Todos esses aspectos são voltados à tentativa de consolidar e transmudar a cultura nacional em conformidade com os parâmetros de uma sociedade democrática, onde a transformação é um ideal permanente, na busca de um corpo social onde o diálogo e a contestação sejam verdadeiramente realizáveis. ${ }^{9}$

6. Ohlin, Jens David. On the very idea of transitional justice. The White head Journal of Diplomacy and International Relations. vol. 8, n. 1, p. 51-68. Disponível em: [http:// papers.ssrn.com/sol3/DisplayAbstractSearch.cfm]. Acesso em: 20.11.2011.

7. Tavares, André Ramos; Agra, Walber de Moura, op.cit., p. 71.

8. "Transitional justice refers to a set of judicial and non-judicial measures that have been implemented by different countries in order to redress the legacies of massive human rights abuses. These measures include criminal prosecutions, truth commissions, reparations programs, and various kinds of institutional reforms". Disponível em: [www.ictj.org]. Acesso em: 23.03.2012.

9. O comprometimento com a redemocratização e a transformação social, a qual se refere a presente pesquisa, é incompatível com a ideia de um instante único e preciso na história. $\mathrm{O}$ avanço rumo à consolidação de uma sociedade substancialmente democrática deve ser associado a uma ideia de transformação permanente, em um corpo social onde o diálogo e a contestação são verdadeiramente possíveis. Ademais, "on that view, transformation is not a temporary phenomenon that ends when we all have access to resources and basic services and when lawyers and judges embrace a culture of justification. Transformation is a permanent ideal, a way of looking at the world that creates a space in which new ways of being are constantly explored and created, 
O tema ganhou particular projeção na década de noventa, e pesquisas apontam as origens do instituto há longa data na história. Arthur, ${ }^{10}$ afirma que o ponto de partida no campo da justiça de transição não é uma questão que se responde com facilidade. Uns defendem que o precedente mais antigo foi o julgamento de Nuremberg, após o fim da Segunda Grande Guerra, outros sustentam as políticas de defesa dos direitos humanos implementadas por Raul Alfonsín após o fim da ditadura militar argentina, mas a doutrina parece não chegar a um consenso.

O caminho trilhado por Teitel ${ }^{11}$ na evolução da questão histórica é dividido em três fases distintas: (1) justiça de transição pós-guerra, (2) justiça de transição pós-guerra fria e, (3) justiça de transição no estado estacionário. ${ }^{12}$

A genealogia da justiça de transição aponta como o grande marco de sua primeira fase, a etapa do pós II Grande Guerra, inaugurada em 1945. Esse período tem como seu maior símbolo os julgamentos realizados no Tribunal de Nuremberg e reflete o triunfo da justiça restaurativa dentro estrutura do direito internacional.

accepted and rejected and in which change is unpredictable but the idea of change is constant". Nesse sentido, vide: Langa, Pius. Stellenbosch University, Prestige Lecture, oct. 2006. Disponível em: [http://sun025.sun.ac.za/portal/page/portal/law/index.afrikaans/nuus/2006/Pius\%20Langa\%20Speech.pdf]. Acesso em: 01.04.2012.

10. "Where to start the history of the field of transitional justice is no easy question to answer. One thinks of the Allies' precedent-setting trials of Nazi war criminals at Nuremberg, or of the human rights policies of Argentinean president Alfonsín after the end of the military junta. But the measures we now associate with transitional justice certainly are nothing new. In Stay the Hand of Vengeance, Gary Bass recounts a history of war crimes tribunals that extends at least 200 years in the past. In Closing the Books: Transitional Justice in Historical Perspective, John Elster has written about trials and purges more than 2000 years ago, during political upheavals in ancient Athens (...) Thus, for Ruti Teitel, the Nuremberg Tribunal is an important moment in the first "phase" of transitional justice (...) I argue that the field began to emerge in the late 1980s, as a consequence of new practical conditions that human rights activists faced in countries such as Argentina, where authoritarian regimes had been replaced by more democratic ones". ARTHUR, Paige. How "transitions" reshaped human rights: a conceptual history of transitional justice. Human Rights Quarterly 31. Maryland: Johns Hopkins University Press, 2009. p. 321-367.

11. Teitel, Ruti. Transitional justice genealogy. Symposium Human Rights in Transition. 16 Harvard Human Rights Journal, p. 69-94, 2003.

12. Na obra original, as três fases da justiça de transição estão elencadas como: Phase I: postwar trasitional justice; Phase II: post-cold war transitional justice; Phase III: steadystate transitional justice. Idem, p. 69. 
Não obstante a referência tradicional a este marco temporal, Teite ${ }^{13}$ afirma que a história começa, na realidade, um pouco antes durante o intervalo entre o fim da I Grande Guerra e o começo da II Guerra na tentativa de delinear o que seria um conflito injusto e na busca pelos parâmetros punitivos no cenário internacional. Como punir a Alemanha pelas agressões perpetradas durante a I Guerra? Qual forma de responsabilização? Nacional ou internacional?

Em termos de justiça, não se olvidava que os vencedores não poderiam, mais uma vez, incidir nos erros das cláusulas do Tratado de Versalhes, estabelecidas pelos Aliados sem qualquer diálogo com a Alemanha. O aludido tratado, em breve síntese, restituiu à França a Alsácia-Lorena, uma parcela de território à Bélgica, retornou aos polacos as terras com que os alemães haviam ficado, além de estipular uma indenização com o primeiro pagamento de cinco bilhões de dólares em marcos-euro, sendo que parte desta reparação deveria se dar in natura através de carvão, navios, madeira e gado. O que mais feriu, todavia, o orgulho alemão foi a redução de suas forças armadas ao número de 100 mil voluntários, além da proibição de que possuíssem aviões e tanques. Assim, os termos do Tratado de Versalhes foram como um golpe arrasador para o povo alemão, o que deflagrou uma grave crise econômica e uma série de comícios irados em todo o país, o que por certo ao longo dos anos propiciou um campo fértil para o chamado hate speech, desenvolvido durante a vigência do nacional socialismo, ${ }^{14}$ que alavancaram a Alemanha rumo a II Guerra. Os julgamentos do Tribunal de Nuremberg tiveram o cuidado de não reincidir nos erros cometidos após a I Grande Guerra.

Com o final da II Guerra e a derrota do nazismo, em 8 de agosto de 1945, durante a conferência de Londres, as quatro potências vencedoras celebraram acordo destinado a estabelecer as regras que deveriam orientar o processo e julgamento dos criminosos de guerra das potências do Eixo. Esse acordo ficou conhecido como a Carta do Tribunal Internacional Militar, conhecido como o Tribunal de Nuremberg, ${ }^{15}$ o primeiro grande moirão sobre a justiça de transição.

13. Idem, p. 72.

14. Shirer, William L. Ascensão e queda do Terceiro Reich. Rio de Janeiro: Civilização Brasileira, 1962. vol. I, p. 101.

15. Explica Japiassú que "as penas capitais foram executadas no dia 16 de outubro de 1946, na própria prisão de Nuremberg, por enforcamento. Após, os restos mortais foram jogados em uma afluente do rio Isar, para que se evitassem futuras glorificações". JAPIASsú, Carlos Eduardo Adriano. O Tribunal Penal Internacional. A internacionalização do direito penal. Rio de Janeiro: Lumen Juris, 2004. p. 48. 
Em que pesem as críticas formuladas por Kelsen ${ }^{16}$ àquela formulação, em razão de se cuidar de típico tribunal ad hoc criado pelos vitoriosos, contrapondo-se aos princípios da legalidade e do juiz natural, por conta da realização de julgamentos de fatos pretéritos ao seu estabelecimento, por outro lado, aponta-se como méritos da primeira fase da justiça de transição foram o forte internacionalismo, a inédita cooperação entre Estados soberanos e a criminalização de condutas violadoras do direito humanitário, que constituíram a base do direito internacional e a primeira noção de accoutability. ${ }^{17}$

A segunda fase da evolução da justiça pós-conflito - Phase II: Post-cold war transitional justice - está relacionada diretamente ao colapso da União Soviética, ${ }^{18}$ e o fim do mundo bipolar, fato este que fez estourar uma onda de transições de governos autoritários rumo ao regime democrático, em especial os países do leste europeu com o fim da cortina de ferro. ${ }^{19}$

Caracterizada especialmente pela ausência de julgamentos internacionais com o reconhecimento das dúvidas e dilemas inerentes aos períodos de fluxo político, surge a reflexão sobre os valores atinentes aos princípios de justiça e a adesão ao rule of law. ${ }^{20}$

16. Kelsen, Hans. Will the judgement in Nuremberg Trial constitute a precedent international Law? The International Law Quaterly. vol. 1, n. 2, p. 158-171.

17. O termo accoutability, neste sentido, se refere à prestação de contas pela revelação da realidade cruel da Segunda Guerra, em particular, do extermínio dos judeus pelos nazistas e pela brutalidade da agressão japonesa na China, o que provocou a criação de dois tribunais internacionais, o de Nuremberg e o de Tóquio, e com eles a definição, pela primeira vez, dos crimes internacionais próprios. JAPIAssú, Carlos Eduardo Adriano, op. cit., p. 43.

18. O que levou a União Soviética com rapidez crescente para o precipício foi a combinação de glasnost, que equivalia à desintegração de autoridade, com uma perestroika que equivalia à destruição dos velhos mecanismos que faziam a economia mundial funcionar, sem oferecer qualquer alternativa; e consequentemente o colapso cada vez mais dramático do padrão de vida dos cidadãos. Nesse sentido, vide: HobSBAwn, Eric. Era dos extremos. O breve século XX - 1914-1991. Trad. Marcos Santa Rita, revisão técnica Maria Célia Paoli. 2. ed., 44. reimp. São Paulo: Cia. das Letras, 1995. p. 468.

19. "A genealogical perspective illuminates the conection between these political transitions and illustrates how many local conflicts were supported by United States/Soviet bipolarism". Teitel, Ruti. Transitional justice... cit., p. 75.

20. "In development of constitucionalism, Rule of Law was within the first developed group of concepts standing against potential power abuses. Rule of Law - while not entirely uncontested - entails at least the following principles: power according to law, power exercise checked with judicial review, legal certainty and legal clarity (...). The rule of law concern in transitional justice is ameliorated in a similar 
Vale lembrar que, enquanto na primeira fase foi assumida a busca pela punição às violações de direitos humanos, na segunda fase surgiu a tensão entre os conceitos de anistia e punição. Isso significa o reconhecimento da importância da anistia como instrumento de negociação nos processos de $\mathrm{paz}^{21} \mathrm{e}$ o abandono, em parte, da ideia da imprescindibilidade da persecução penal nos períodos de restauração dos regimes políticos de liberdade. Isso porque a tentativa de se impor accountability tão somente através de processos criminais, muitas vezes é colocada em cheque diante da manifesta imposição de limites estabelecida pelo próprio rule of law no exercício do jus puniendi, tal como a questão da legalidade, da qual decorrem a irretroatividade da lei penal e o questionamento a respeito do alto grau de seletividade nas persecuções penais. O reconhecimento desses profundos dilemas conduziu muitos países à renúncia das persecuções penais e ao desenvolvimento em favor de métodos alternativos de busca pela verdade e accountability. ${ }^{22}$

Daí à noção de que a concretização da justiça na busca da reconstrução da nação não está atrelada necessariamente à questão criminal, adotando-se uma perspectiva mais ampla, que envolve o desenvolvimento de condições favoráveis à cicatrização das feridas causadas no tecido social pelos regimes políticos precedentes para incorporar os valores que decorrem da concepção de Estado de Direito, tais como a paz e a reconciliação nacional.

Cronologicamente situada no fim do século XX, associada ao fenômeno da globalização, surge a terceira fase da justiça de transição relacionada ao comprometimento com a persecução dos atos atentatórios à humanidade. ${ }^{23}$ Este momen-

light". Assim, o estabelecimento do Rule of Law é um tema de contato entre a justiça de transição e o constitucionalismo de transição. Vide: Jiunn-Rong, Yeh; Wen-Chen, Chang. The changing landscape of modern constitucionalism: transitional perspective. National Taiwan University Law Review, vol. 4, n. 1, p. 145-183. Disponível em: [http:ssrn.com/abstract=1482863]. Acesso em: 10.05.2012.

21. Ambus, Kai. O marco jurídico da justiça de transição. In: ; ZILLI, Marcos; MouRA, Maria Thereza Rocha de Assis; Monteconrado, Fabíola Girão. Anistia, justiça e impunidade: reflexões sobre a justiça de transição no Brasil. Belo Horizonte: Fórum, 2010. p. 65.

22. "The attempt to impose accountability through criminal law often raised rule-of-law dilemmas, including retroactivity in the law, tampering with existing laws, a high degree of prosecutorial selectivity (...). These profound dilemmas were recognized in the deliberations preceding the decisions in many countries to forgo prosecutions in favor of alternative methods for truth seeking and accountability". TeItEL, Ruti. Transitional justice... cit., p. 76.

23. Idem, p. 89. 
to coincide com a convicção de que a proteção dos direitos humanos não deve ser reduzida ao âmbito da atuação estatal, uma vez revelado o legítimo interesse internacional na tutela dessa esfera do conhecimento humano. Isso impulsionou o estabelecimento de um sistema internacional de preservação e monitoramento do direito das gentes, o que teve como consequência a convicção de que a violação desses direitos foi elevada ao patamar de autêntica preocupação universal. ${ }^{24}$

Se por um lado, na análise do sistema internacional de proteção do direito humanitário, criada na virada do século, a Declaração Universal de Direitos Humanos representa uma afirmação simplesmente recomendatória, ${ }^{25}$ por outro, a criação do Tribunal Penal Internacional (International Criminal Court ICC ) 26 "representou o clímax de um longo processo histórico rumo ao estabelecimento de um sistema internacional de justiça penal" ${ }^{27}$ com força coercitiva para os países signatários de sua convenção.

Vale lembrar que a criação do TPI foi precedida pela criação de tribunais internacionais ad hoc para julgar crimes contra a humanidade, como foi o caso dos Tribunais Penais Internacionais para a Antiga Iugoslávia e Ruanda, ambos criados por resoluções do Conselho de Segurança da ONU, ${ }^{28}$ que se mostrou

24. Piovesan, Flávia. Direitos humanos e o direito constitucional internacional. 7. ed. São Paulo: Saraiva, 2006. p. 161.

25. Idem, p. 332-334.

26. Sítio eletrônico ICC. Disponível em: [www.icc-cpi.int/]. Acesso em: 24.05.2012.

27. Zilli, Marcos. O último tango? In: SoARes, Inês Virgínia Prado; KISHI, Sandra Akemi Shimada (coords.). Memória e verdade: a justiça de transição no Estado Democrático brasileiro. Belo Horizonte: Fórum, 2009. p. 99. Ainda, Ruti Teitel afirma: "The most recognized symbol of the normalization of transitional jurisprudence is the entrenchment of the Phase I response in the form of International Criminal Court ('ICC'), the new international institution established at the end of the twentieth century. This court was preceded by the 'ad hoc' international criminal tribunals convened to respond to genocidal conflicts in Balkans and Rwanda. Half a century after the World War II, the ICC symbolizes the entrenchment of the Nuremberg model: the creation of a permanent international tribunal appointed to prosecute war crimes, genocide, and crimes against humanity as a routine matter under international law". Teitel, Ruti. Transitional justice... cit., p. 90.

28. ONU. Resolução 771, de 13.08.1992, do Tribunal Penal Internacional para a antiga Iugoslávia. Disponível em: [http://daccess-dds-ny.un.org/doc/UNDOC/GEN/ N92/379/72/IMG/N9237972.pdf?OpenElement]. Acesso em: 24.05.2012; e Resolução 955, de 08.11.1994, para o Tribunal Penal Internacional para Ruanda. Disponível em: [http://daccess-dds-ny.un.org/doc/UNDOC/GEN/N95/140/97/PDF/N9514097. pdf?OpenElement]. Acesso em: 24.05.2012. 
alarmado com as notícias referentes às desumanidades cometidas no território correspondente à antiga Iugoslávia, especialmente na Bósnia, Kosovo e em Ruanda, na cidade de Kigali. ${ }^{29}$

Antes de se atingir a institucionalização do TPI havia, contudo, Estados que se opunham fortemente à implementação dessa Corte, dentre os quais se destacavam os Estados Unidos, a China, a Índia e Israel. ${ }^{30} \mathrm{Na}$ conferência diplomática de Roma, realizada de 15 de junho a 17 de julho de 1998, o Tribunal foi aprovado com 120 votos a favor, 7 votos contrários (Estados Unidos, Filipinas, China, Índia, Israel, Sri Lanka e Turquia), além de 21 abstenções. O Estatuto foi depositado em Nova Iorque a espera que fosse aderido, ao menos, por 60 Estados, sendo certo que tal número foi atingido no dia 11.04.2002. ${ }^{31}$

Mais de meio século após a criação do Tribunal de Nuremberg, o Tribunal Penal Internacional representa efetivamente o fim do modelo de tribunais ad hoc criados para julgamentos de fatos anteriores a sua criação, uma vez que se trata de um tribunal permanente com o propósito de processar e julgar crimes contra a humanidade.

Reforçando tal ideia, o artigo 22 do Estatuto de Roma ${ }^{32}$ faz previsão expressa do princípio da legalidade (Nullum crimen nulla poena sine lege), do qual decorrem, segundo Nilo Batista, ${ }^{33}$ os seus 4 consectários lógicos: (1) proibir a retroatividade da lei penal mais gravosa (nullum crimen nulla poena sine lege praevia), (2) proibir a criação de crimes e penas pelo costume (nullum crimen nulla poena sine lege scripta), (3) proibir o emprego da analogia in malan partem para criar delitos (nullum crimen nulla poena sine lege stricta), (4) proibir incriminações vagas e indeterminadas (nullum crimen nulla poena sine lege certa).

Prevê o Estatuto, ademais, que o TPI somente terá competência para julgar crimes cometidos após a sua entrada em vigor (artigo 24), além de uma série de outros direitos em prol da consolidação de um processo penal de garantias para os acusados e que não padeça dos mesmos defeitos dos tribunais ad hoc anteriormente formados. Não se pode deixar de ter em conta que a terceira fase

29. Japiassú, Carlos Eduardo Adriano, op. cit., p. 86-108.

30. Idem, p. 112.

31. Idem, p. 113.

32. BRASIL. Decreto 4.388, de 25.09.2002. Promulga o Estatuto de Roma do Tribunal Penal Internacional. DOU 26.08.2002. Disponível em: [www.planalto.gov.br/ccivil_03/ decreto/2002/D4388.htm]. Acesso em: 28.05.2012.

33. Batista, Nilo. Introdução crítica ao direito penal. Rio de Janeiro: Revan, 2003. p. 65-83. 
da justiça de transição representa a lógica de um sistema global de proteção ao direito humanitário, exteriorizado por mecanismos que viabilizem uma persecução penal no plano internacional, expurgando os vícios contidos nos julgamentos de Nuremberg e implementando os fundamentos da paz perpétua, da cidadania e da complementaridade.

Analisadas essas considerações, a fim de possibilitar uma perspectiva geral da questão relacionada às mudanças de regimes políticos, passa-se a análise específica das dificuldades que o Brasil enfrenta atualmente.

\section{REFLEXõES ACERCA dOS LIMITES dO DEBATE PENAL NO CENÁRIO BRASILEIRO}

No cenário interno, após mais de duas décadas de reabilitação do regime de liberdades, a partir da ótica da tutela universal do direito humanitário, a proposição do passado recente ganha dimensão no meio político, acadêmico e social. Significa dizer que após a retomada da ordem democrática, surge um movimento com o desafio de investigar a memória do país durante um período que parecia estar sob um pacto de silêncio (1964/1985) e, pelo que parece, o assunto vem inflamando diversos setores na sociedade. A título de exemplo, no dia 29.03.2012, em clima de violência urbana e repressão policial terminou o encontro entre dois grupos que manifestavam ideias um tanto divergentes no Rio de Janeiro. De um lado, militares da reserva que promoviam, na sede do Clube Militar da cidade, uma comemoração do aniversário de 48 anos do golpe militar de 1964, e do outro, um grupo que fazia uma passeata com gritos que ecoavam pelas ruas da cidade com o pedido de punição para os crimes da ditadura militar. ${ }^{34}$

Não é prudente que o retratado descrito na reportagem da grande mídia, seja refletido com a mesma feição no meio acadêmico. Como adverte Michel Foucault, ${ }^{35}$ "o discurso não é simplesmente aquilo que traduz as lutas ou os sistemas de dominação, mas aquilo por que, pelo que se luta, o poder de que queremos nos apoderar". É preciso delimitar a ordem da fala a respeito da proteção e promoção do direito das gentes, uma vez que todo Estado comprometido com a comunidade internacional supõe a rejeição a qualquer ato atentatório

34. Góes, Bruno. Tumulto no encontro de atos pró e contra golpe. Manifestantes cobram punição para crimes da ditadura e entram em conflito com militares que comemoravam a data. O Globo, Cad. O País, Rio de Janeiro, 30.03.2012, p. 13.

35. Foucault, Michel. A ordem do discurso. Aula inaugural do College de France, pronunciada em 2 de dezembro de 1970. 21. ed. São Paulo: Loyola, 2011. p. 10. 
à humanidade. A noção de democracia, todavia, que orienta este trabalho parte da premissa de que a desejável responsabilização pelas violações não pode ser objeto de retórica política, tampouco produto de emoção, pois se a omissão não é justiça, o excesso também é repudiado pelos direitos fundamentais no âmbito interno dos Estados.

Afirma-se isso porque, cada vez com mais destaque, desenvolvem-se trabalhos em relação ao problema de saber se os responsáveis pelas condutas criminosas da repressão política, promovida pelo regime de 1964/1985, devem ser penalmente responsabilizados e, em sendo a resposta positiva, como viabilizar a persecução penal.

Sob esse prisma, entre os que são contra e os que são a favor da punição, apresentam-se uma série de argumentos, cada qual com suas razões de persuasão. Pretende-se assim, estabelecer-se um diálogo entre os argumentos, diante da complexidade que o problema possui.

É preciso antes, contudo, uma sucinta elucidação. Segundo o princípio da presunção de inocência, previsto no consagrado art. $5 .^{\circ}$, LVII, da CF/1988, é duvidosa a afirmação de que violações foram praticadas pelos agentes públicos da repressão política, uma vez que, ao menos do ponto de vista jurídico, não há qualquer condenação criminal com trânsito em julgado sobre esses fatos, de sorte que "se alguém perguntar se agentes estatais ou colaboradores do regime militar cometeram crimes nos porões da ditadura, juridicamente, a resposta é não" ${ }^{36}$ Por outro lado, quando milhares de depoimentos narram crimes previstos no Código Penal vigente à época, praticados nas mesmas condições de tempo, em diferentes locais do território nacional, através de semelhantes formas de execução, e por agentes "a serviço do Estado", como as declarações apresentadas no livro Direito à memória e à verdade, ${ }^{37}$ da Secretaria de Direitos

36. Swensson Junior, Lauro Joppert. Punição para os crimes da ditadura militar. Contornos do debate. In: Dimitri, Demoulis; Martins, Antonio; Swensson Junior, Lauro Joppert (orgs.). Justiça de transição no Brasil - Direito, responsabilização e verdade. São Paulo: Saraiva, 2010. p. 24.

37. Formada a partir da Lei 9.140/1995, a Secretaria de Direitos Humanos e a Comissão Especial de Mortos e Desaparecidos levaram juntas 11 anos para reunir em um documento oficial do Governo Federal que corrobora acusação aos órgãos de repressão do regime político passado por abusos e excessos praticados por seus integrantes. Nesse sentido, vide: Brasil. Secretaria Especial dos Direitos Humanos. Comissão Especial sobre Mortos e Desaparecidos Políticos, 2007. Disponível em: [http://portal.mj.gov. br/sedh/biblioteca/livro_direito_memoria_verdade/livro_direito_memoria_verdade_ sem_a_marca.pdf]. Acesso em: 25.05.2012. 
Humanos e da Comissão Especial de Mortos e Desaparecidos Políticos, pode ser dado como fato histórico que tais ilícitos foram praticados. ${ }^{38}$

Ultrapassados esses pontos, e considerando ainda a terceira fase da justiça de transição proposta por Teitel, as duas principais linhas argumentativas são feitas através das proposições de que: (1) os delitos de lesa-humanidade são imprescritíveis e, (2) de que a Lei de Anistia (Lei 6.683/1979) ${ }^{39}$ não é uma lei válida. ${ }^{40}$ Esses argumentos possuem como pano de fundo a afirmação dos direitos humanos, e se operam a partir da lógica de que a manutenção da persecução penal, enquanto possibilidade, funcionaria como um elemento de prevenção, ou ainda de prestação contas à coletividade. Vale dizer, a persecução penal de crimes contra a humanidade está no projeto de luta global contra a impunidade. ${ }^{41}$

\subsection{Breve análise das anistias}

No que tange à anistia, pode se afirmar que é um instrumento de negociação nos processos de paz. Contudo, a dificuldade que surge é no que diz respeito às condições em que pode ser concebida. A partir dessa marcação, é necessário esclarecer que existem duas formas de concessão de anistia, ${ }^{42}$ a saber, aquelas absolutas e as condicionadas.

Explica Ambus que as anistias absolutas se caracterizam como "aminésicas", uma vez que seu designo é esconder crimes do passado proibindo qualquer investigação. São, pois, o desfecho de um compromisso político para por

38. Swensson Junior, Lauro Joppert, op. cit., p. 25. Ver, ainda: Fausto, Boris. História concisa do Brasil. São Paulo: Edusp, 2009. p. 257-263. "Sob a justificativa de livrar o Brasil das ameaças de implementação do regime comunista", com a proposta de restaurar a democracia, o golpe criou as bases para a ampliação do aparato repressor, a que ficavam sujeitos os responsáveis pela prática de crimes contra o Estado, contra a ordem política e social, ou por atos de guerra revolucionária".

39. BRASIL. Lei 6.683, de 21.08.1979. Concede a anistia e dá providências. DOU 28.08.1979. Disponível em: [www.planalto.gov.br/ccivil_03/Leis/L6683.htm]. Acesso em: 28.05.2012.

40. Mello, Osvaldo Aranha Bandeira. Imprescritibilidade dos crimes de tortura. In: SoARES, Inês Virgínia Prado; Kishi, Sandra Akemi Shimada (coords.). Memória e verdade: a justiça de transição no Estado Democrático brasileiro. Belo Horizonte: Fórum, 2009. p. 135-139.

41. Ambus, Kai, op. cit., p. 37.

42. Idem, p. 66-81. 
fim a um conflito ou facilitar um processo de transição, dado que neste último caso podem ser nomeadas de "anistias de compromisso".

As críticas que se fazem a essa modalidade se dão pelo fato de que as mesmas conduzem ao desamparo as vítimas e a perpetuação da impunidade. Elas impedem a identificação dos autores e trazem um verdadeiro obstáculo à luta pela apuração dos fatos que realmente ocorreram, implicando isso não somente em um empecilho na luta pela memória nacional, assim também como no direito das famílias das vítimas a terem os restos mortais de seus familiares identificados e sepultados (memória democrática e direito ao luto), ${ }^{43}$ o que é mais um instrumento em prol da reconciliação e pacificação nacional. Assim, o Estatuto de Roma, que regulamenta o $\mathrm{TPI}^{44}$ expressa seus compromissos no combate à impunidade, dentro da premissa da terceira fase da justiça de transição, assim também como afirma o respeito aos demais princípios de justiça, em especial, a paz perpétua, a cidadania, a reserva legal e a complementaridade.

De outro lado, há a chamada anistia condicionada, que não exime automaticamente de punição os autores de atos cometidos durante certos lapsos de tempo, e subordinam o benefício (extinção da punibilidade) à realização de certos feitos. Em outras palavras, os antigos atores políticos devem realizar atos com vista a cumprir o núcleo do elemento justiça, ou seja, satisfazer a legítimos reclamos nacionais, em especial, revelar completamente os fatos ocorridos, reconhecer suas responsabilidades, o arrependimento etc. Esse modelo pode ser exemplificado através da experiência sul-africana que sobrevalorizou a reconciliação nacional como pilar central da reconstrução sociopsicológica pós-conflito. Sob esse prisma, retrata a concepção de justiça de forma a integrar as comunidades cindidas pelo regime do aparthaid social e foi capaz de restabelecer o diálogo entre as vítimas e seus agressores. ${ }^{45}$

No caso brasileiro, a Lei de Anistia (Lei 6.683/1979) foi revisada pelo art. 8. ${ }^{\circ}$ do ADCT que, posteriormente, foi regulamentado pela Lei 10.559/2002, a qual dispõe sobre o regime do anistiado político, e prevê, inclusive, compen-

43. Sobre memória democrática e direito ao luto, vide: SoAREs, Inês Virgínia Prado. Memória democrática e desaparecidos políticos. In: ; KisHi, Sandra Akemi Shimada (coords.). Memória e verdade: a justiça de transição no Estado Democrático brasileiro. Belo Horizonte: Fórum, 2009. p. 317-340.

44. Brasil. Decreto 4.388, de 25 de setembro de 2002. Promulga o Estatuto de Roma do Tribunal Penal Internacional cit.

45. Valle, Vanice Lírio; Menezes, Luciana. Justiça de transição e direitos humanos: dilemas na afirmação de um direito a esquecer. A \& $C$ Revista de Direito Administrativo e Constitucional, n. 48, ano 12. 
sação econômica de caráter indenizatório. O governo brasileiro prosseguiu no esforço pela reconciliação nacional e, no dia 18.11.2011, através da Lei 12.528, criou a Comissão Nacional da Verdade ${ }^{46}$ destinada a se engajar na luta contra o esquecimento (struggle against forgetting). ${ }^{47}$

Ainda sob influência da terceira fase da justiça de transição, a Lei 6.683/1979 foi submetida a controle de constitucionalidade - na via concentrada - através da Arguição de Descumprimento de Preceito Fundamental 153,48 na qual a Ordem dos Advogados do Brasil questionou a validade dos dispositivos que concederam anistia aos agentes públicos que participaram dos atos de excesso praticados pelo regime antecedente que, em tese, estariam a contrariar o sistema internacional de proteção e monitoramento das violações perpetradas contra o direito humanitário. A Corte Constitucional Brasileira decidiu no sentido da inaplicabilidade àquela norma, qualificada como lei-medida dos parâmetros emanados de instrumentos convencionais internacionais posteriores, sendo de se empreender à sua interpretação segundo a realidade vigente à época de sua

46. Idem.

47. Dimoulıs, Dimitri. Justiça de transição e função anistiante no Brasil. Hiposiações indevidas e caminhos de responsabilização. In: Dimitri, Demoulis; Martins, Antonio; SwEnsson JunIor, Lauro Joppert (orgs.). Justiça de transição no Brasil - Direito, responsabilização e verdade. São Paulo: Saraiva, 2010. p. 105. Sobre críticas à denominação "direito à verdade": "Exigir que o Estado adote e divulgue certas 'verdades' históricas viola o imperativo da neutralidade estatal diante crenças e posições dos indivíduos. Esse imperativo decorre do dever estatal de respeitar a liberdade de opinião (art. 5. ${ }^{\circ}$, IV, da CF/1988), de prestar o pluralismo político (art. 1. ${ }^{\circ}, \mathrm{V}, \mathrm{da} \mathrm{CF} / 1988$ ), assim como o da proibição de criar preferências entre brasileiros, enquanto especificação do princípio da igualdade (art. 19, III, da CF/1988). Eventual "direito à verdade" a ser satisfeito mediante prestação estatal contraria o princípio democrático que tem como componente central o pluralismo e a tolerância (...). Os interessados podem se engajar na "luta contra o esquecimento" (struggle against forgeting). Perecem-nos louváveis no contexto brasileiro os esforços de associações de vítimas da ditadura e de diversas ONGs para sensibilizar politicamente a população que pouco se interessa pelos fatos ocorridos no período da ditadura e também para corrigir a imagem da ditadura difundida pela mídia que banaliza a violência estatal (como referência à "ditabranda"). Mas não pode ser admitido constitucionalmente que a luta em prol de determinados posicionamentos e interesses políticos apresente-se como exercício de um direito à verdade, atribuindo juridicidade a algo inexistente, em típica postura de hipostasiação". A título de exemplo: Cf. Uribe, Gustavo; Bruno, Cássio. O Globo, Cad. 1, Rio de Janeiro, 15.05.2012, p. 11. Foi manchete do jornal: "Não tem dois lados, o outro lado foi assassinado". Integrantes da Comissão da Verdade já se dividem sobre o foco da investigação, centrada nos crimes de agentes públicos.

48. Brasil. STF. Rel. Min. Eros Grau. Disponível em: [www.stf.jus.br/arquivo/cms/noticiaNoticiaStf/anexo/ADPF153.pdf]. Acesso em: 29.05.2012. 
promulgação. ${ }^{49}$ Desta forma, a anistia de 1979 era abrangente e também anistiava os agentes da repressão no período compreendido entre 02.09.1961 e 15.08.1979, portanto esses atos não seriam passíveis de nenhuma punição.

Inúmeras críticas foram destinadas à decisão que, em síntese, resumem que aludido acórdão deu por encerrada essa delicada questão ao preço de ignorar o conceito de crimes de lesa-humanidade e dissociar o conceito de democracia dos direitos humanos. Assim, o acórdão teria legitimado a ditadura militar "na medida em que reconheceu os golpistas de 1964 como sujeitos legítimos". Alegou-se ainda que, ao contrário do decidido, a Constituição de 1988 estabeleceu que o Estado Democrático de Direito tem como um dos seus fundamentos a dignidade da pessoa humana (art. 1. ${ }^{\circ}, \mathrm{III}$ ), e rege-se em suas relações internacionais segundo a prevalência dos direitos humanos (art. $4 .^{\circ}$, II). Ao tratar dos direitos fundamentais, a Lei Maior vedou a prática da tortura e o tratamento desumano e degradante, tendo considerado crimes inafiançáveis e insuscetíveis de graça ou anistia a prática da tortura e o terrorismo..$^{50}$

\subsection{Análise critica do argumento da prescrição}

Por ocasião do acima narrado, é necessário saber se as alegações expostas, também estariam aptas a se transpor ao instituto da prescrição penal. A advertência é de Nilo Batista que, após ter elaborado trabalho crítico logo após a edição da Lei de Anistia em $1979^{51}$ no qual condenava as disposições da mesma, mudou a sua posição em relação à possibilidade da persecução penal dos agentes do antigo regime.

Muito embora a discussão em torno do tema seja permeada por "sentimentos tão respeitáveis quanto discutíveis", sugere o autor que mais de três décadas após a promulgação do aludido diploma, a posição em favor da responsabilização penal no caso brasileiro se torna insustentável. ${ }^{52}$

49. Valle, Vanice Lírio; Menezes, Luciana, op. cit.

50. Cunha, Paulo Ribeiro. Militares e anistia no Brasil: um dueto desarmônico. In: Teles, Edson; Safatle, Vladimir. O que resta da ditadura. São Paulo: Boitempo, 2009. Coleção Estado de Sítio. p. 39.

51. Batista, Nilo. Aspectos jurídicos penais da anistia. Revista de Direito Penal. n. 26. Disponível em: [www.fragoso.com.br/eng/arq_pdf/direito_penal/conteudos/RDP26. pdf]. Acesso em: 29.05.2012.

52. Batista, Nilo. Justiça de transição no Brasil - Direito, responsabilização e verdade. In: Dimitri, Demoulis; Martins, Antonio; Swensson Junior, Lauro Joppert (orgs.). São Paulo: Saraiva, 2010. p. 7. 
Isso porque o questionamento da anistia sucumbiria perante a linha argumentativa do transcurso do lapso previsto em lei para que ocorra a perda da pretensão punitiva (rule of law). Isso porque a refutação ao argumento da imprescritibilidade dos crimes contra a humanidade é implacável: os instrumentos normativos constitucionais somente adquirem força vinculante após o processo constitucional de internalização e o Brasil não subscreveu a Convenção sobre a Imprescritibilidade dos Crimes de Guerra e dos Crimes contra a Humanidade de 1968, nem qualquer outro tratado que contivesse cláusula semelhante. Isso somente veio a acontecer em 25.09.2002, através do já mencionado Dec. 4.388, quando foi promulgado o Estatuto de Roma do Tribunal Penal Internacional ao ordenamento interno.

Mais do que isso, está claro que esse mesmo tratado afirma, em seu corpo normativo de proteção aos direitos humanos, que o TPI tem como fundamento a reserva legal, princípio este igualmente previsto em outros sistemas jurídicos existentes no mundo, a exemplo da Declaração Universal de Direitos do Homem, da 3. ${ }^{a}$ Convenção de Genebra e em seus Protocolos adicionais, além de tratados internacionais para a proteção de direitos humanos, como o Pacto Internacional de Direitos Civis e Políticos, o Convênio Europeu para a Proteção de Direitos Humanos e das Liberdades Fundamentais, na Convenção Interamericana de Direitos Humanos e na Carta Africana de Direitos Humanos e dos Povos, sendo certo afirmar que essa norma serve para conter punições arbitrárias, ${ }^{53}$ além de ter como função histórica impedir a retroatividade da lei penal mais severa. ${ }^{54}$

Nessa linha, afirma-se que os direitos humanos, além de exercerem a importante tarefa de criminalizar os delitos de lesa-humanidade, estabelecem também limites à atuação estatal na contenção do jus puniendi no âmbito dos Estados, em razão da longa história de exercício arbitrário desse mesmo poder. ${ }^{55}$

53. Japiassú, Carlos Eduardo Adriano, op. cit., p. 143-159.

54. Batista, Nilo. Justiça de transição... cit., p. 14.

55. Os Procuradores da República discutem estratégias para investigar crimes do regime militar, evitando a instauração de inquéritos policiais, de forma a impedir a impetração de habeas corpus. Ministério Público Federal traça estratégia para investigar ditadura. Disponível em: [http://oglobo.globo.com/pais/ministerio-publico-federal-traca-estrategia-para-investigar-ditadura-4264597]. Acesso em: 28.05.2012. Ver, ainda: Melossi, Dario; Pavarini, Massimo. Cárcere e fábrica. As origens do sistema penitenciário (séculos XVI e XIX). Rio de Janeiro: Revan, 2006. Nesse mesmo sentido: Foucault, Michel. Vigiar e punir. Petrópolis: Vozes, 2000. 
Portanto, se a imprescritibilidade dos delitos de lesa-humanidade representa uma exceção gravosa na disciplina geral da prescrição por habilitar ampliativamente a persecução e a execução penal, por essa premissa deve submeter-se ao princípio da legalidade, encampada pelo próprio Estatuto de Roma.

\section{REFLEXÕES SOBRE A CONSOLIDAÇÃO DE UM PENSAMENTO DEMOCRÁTICO}

A cautela conduz a ideia de que a busca desenfreada pela punição poderá representar afetação aos pilares do rule of Law. ${ }^{56}$ Não é possível pretender que o Estado Democrático de Direito se transforme em uma "democracia justiceira" armada, nos dizeres de Neves, ${ }^{57}$ da infalível retórica dos direitos humanos e sua força simbólica ambivalente.

A aparente normatização da justiça de transição leva a uma maior tolerância de decisões políticas discricionárias, além da politização do uso da justiça para um aumento de procedimentos irregulares e para um afastamento da lei vigente, justificado pelos termos humanitários ${ }^{58}$ o que não pode ser admitido.

56. Hannah Arendt adverte que nada frearia a determinação do Estado judeu em capturar Adolf Eichmann, um dos arquitetos da "solução final", raptado num subúrbio de Buenos Aires por um comando israelense em maio de 1960. Na obra são descritas reflexões a respeito do anseio punitivo do Estado de Israel que, desrespeitando os limites da soberania argentina, adentrou aquele Estado soberano para, sob a roupagem da refutação à impunidade, exercer o seu ius puniendi. Cf. ARENDT, Hannah. Eichmann em Jerusalém. Um relato sobre a banalidade do mal. Trad. José Rubens Siqueira. São Paulo: Cia. das Letras, 1999.

57. A caracterização da força simbólica dos direitos humanos como ambivalente significa que, de um lado, serve a afirmação generalizada de direitos relacionados com a inclusão jurídica em condições de dissenso estrutural, e de outro, atua como forma de manipulação política, seja para encobrir situações de carência de direitos, seja, mais bruscamente, para dar ensejo a opressão política, implicando, nesse caso, ofensas escandalosas aos próprios direitos humanos. Afirma o autor que é possível observar que vem se desenvolvendo um "imperialismo dos direitos humanos" na discussão acadêmica internacional. Este "imperialismo" não tem apenas um apelo estratégico ou ideológico de asseguramento de hegemonia política (no sentido de Nye), mas também recorre à "moral" e à "razão" (como Habermas). O perigo do recurso a "moral" e à "razão" consiste no fato de que isso pode levar a abusos incontroláveis. NEVES, Marcelo. A força simbólica dos direitos humanos. Revista Eletrônica de Direito do Estado. n. 4. Salvador: Instituto de Direito Público da Bahia, out.-dez. 2005. Disponível em: [www.direitodoestado.com.br]. Acesso em: 29.05.2012.

58. "The apparent normalization of transitional justice is also evident in the toleration of greater politics discretion, politicization in the uses of justice, the rise of highly 
Lutar pela tese da persecução penal dos atores políticos do regime antidemocrático brasileiro, em 1979 era compreensível, pois "ainda havia sangue no piso dos porões, lutava-se pela restauração da legalidade democrática" ${ }^{59}$ Uma vez recomposta a legalidade, o processo de transição e transformação social deve ter como objetivo a preservação de um corpo social onde o diálogo e a contestação sejam verdadeiramente possíveis. ${ }^{60}$

O elemento justiça na cunhagem jurídica da transição deve ser compreendido em sua acepção mais ampla, implicando no reconhecimento dos direitos dos acusados, do bem estar das vítimas e do bem estar da sociedade em longo prazo. Nesse passo, a justiça restaurativa supõe muito mais do que aquela penal retributiva, que se justifica no elemento da prevenção, do combate à impunidade e na (suposta) "bondade do poder punitivo" ${ }^{61}$ Numa perspectiva crítica, Ohlin ${ }^{62}$ traz o questionamento se a justiça de transição é de natureza

irregular procedures, and explicit departures from prevailing law, all justified in humanitarian terms". Teitel, Ruti. Transitional justice... cit., p. 92.

59. Batista, Nilo. Justiça de transição... cit., p. 13.

60. Langa, Pius, op. cit.

61. Adverte Salo de Carvalho que, diante da crença na regularidade dos atos do poder, é deflagrada uma verdadeira crise que se reflete entre as distâncias das práticas penais e a expectativa democrática do exercício do jus puniendi. Carvalho, Salo. Antimanual de criminologia. Rio de Janeiro: Lumen Juris, 2011. p. 81-82.

62. "Is transitional justice some other kind of justice, fundamentally different from justice during non-transitional moments? Or is simply ordinary justice, a familiar endstate that remains elusive because a society has been ripped apart? (...) A view of transitional justice as ordinary justice requires that the basic rules of justice apply in all situations, including extraordinary moments after genocide, war, and ethic conflicts. This view of justice also implies many defendant centered protections: that due process of law is respected (both in procedure and substance), that criminal defendants are punished according to public and prospective laws, and that procedural protections are for defendants are a precondition of meaningful justice. (...) The right to counsel, the right to remain silent, the right to confront witnesses and evidence are all constructive of due process and the notion of a fair trial. (...) This is to be contrasted with transitional justice as a special kind of justice, where the regular rules of justice are supplanted by novel rules justified by the extraordinary nature of moral fissure. The conception of transitional justice as a special kind of justice is particularly susceptible to specious arguments. As suggested en the previous section, special justice encourages revision of the ordinary principles of justice in service of the laudable goal of restoring collective peace and security. Although this might be warranted in some circunstances, I will suggest here that the basic structure of this argument is dangerous and might spawn unfortunate conclusions. Although this might be warranted in some circumstances, I will suggest here that the basic 
ordinária ou extraordinária. Se for analisada em sentido comum (ordinária) é necessário que sejam observados todas as regras e princípios de direito, em toda e qualquer situação, incluídos nessa premissa os momentos pós-conflitos, quando, normalmente, há a necessidade de se lidar com casos de crimes de guerra, genocídio e conflitos étnicos. De outro lado, a justiça transicional, caso examinada como justiça extraordinária, incentiva a revisão e a releitura de normas que a materializam através da justificativa de existência de uma fissura no tecido social, o que encoraja argumentos ilusórios e enganadores, baseados na retórica de restauração da paz. A estrutura básica desse argumento pode findar-se em infelizes conclusões, dado que há uma benevolência à abertura de exceções na aplicação de regras básicas de justiça, o que pode abrir a porta para a criação de um juízo de exceção.

Exigências de responsabilização e justiça por parte das vítimas com frequência entram em conflito com os esforços pela paz e reconciliação. Desta forma, abrir mão de uma persecução penal é, às vezes, uma condição necessária para facilitar essa mesma paz e a reconciliação. Uma definição de justiça de transição centrada na vítima não leva suficientemente em conta esta tensão. Em tempos de transição e transformação, uma política de persecução penal tem o potencial de inviabilizar uma passagem pacífica de um governo autoritário para um democrático. ${ }^{63}$

Honesto é o questionamento que se insurge em face da proibição da investigação dos fatos ocorridos a partir do argumento preclusivo da prescrição. Como já dito, o óbice à persecução penal dos agentes do regime superado, em razão do transcurso do lapso previsto em lei, para que ocorra a prescrição da pretensão punitiva estatal, é um consequente lógico da acepção do rule of law. Contudo, isso jamais poderá caracterizar um obstáculo à luta pela apuração dos fatos que realmente ocorreram, implicando isso não somente na luta pela memória nacional, assim também como no direito das famílias das vítimas a terem os restos mortais de seus familiares identificados e sepultados, o que é mais um mecanismo em prol da reconciliação e pacificação nacional.

Entre as posições extremas da integral persecução ou do integral esquecimento, transitam outras propostas intermediárias que ganham maior relevân-

structure of this argument is dangerous and might spawn unfortunate conclusions". Ohlin, Jens David. On the very idea of transitional justice. The Whitehead Journal of Diplomacy and International Relations, vol. 8, n. 1, p. 51-68. Disponível em: [http:// papers.ssrn.com/sol3/DisplayAbstractSearch.cfm]. Acesso em: 20.11.2011.

63. Ambus, Kai, op. cit., p. 30. 
cia do que eventuais práticas retributivas. A questão, pelo que parece, está em saber se esse mesmo efeito - de reforço dos direitos humanos - não se pode alcançar através de alternativas, que não exclusivamente a imputação penal. ${ }^{64}$

Escaparia aos objetivos do presente trabalho enfrentar pormenorizadamente cada uma das alternativas à persecução penal. Destacam-se, contudo, as iniciativas apontadas pelo International Center of Transitional Justice (ICTJ) ${ }^{65}$ no sentido de viabilizar reparações cíveis, esforços para a instituição de um dia nacional do luto em favor dos seres humanos vitimados pelo período de exceção, reformas com o propósito de resgatar a credibilidade das instituições públicas, estabelecimento de comissões "da verdade", além de iniciativas políticas em favor da luta contra o esquecimento através, por exemplo, da criação monumentos, museus e renomeação de espaços públicos. Em síntese, não se pode pretender que o processo de transformação social em busca da consolidação de uma cultura substancialmente democrática se dê a partir do direito penal.

\section{Conclusão}

A justiça de transição tem o declarado compromisso com a reconstrução das nações que atravessaram períodos de conflitos armados ou regimes autoritários, bem como o restabelecimento do rule of law, o comprometimento com a luta contra o esquecimento pelos abusos sofridos (memória nacional democrática), e a promessa de reparação das vítimas pelos excessos sofridos através da violação do direito humanitário.

Sobre o último aspecto surge no Brasil, em razão da barbárie praticada durante o período de exceção, o argumento da imprescindibilidade da persecução penal e, a partir dessa fala, o empenho pela punição dessas infrações. Dentro dessa ótica, de acordo com a terceira fase da genealogia examinada, surge o ideal da busca pela responsabilização penal através das disposições do direito internacional dos direitos humanos ${ }^{66}$ e, em especial, o Estatuto de Roma. Destaca-se no centro dessa busca o preceito que afirma que os crimes de lesa-humanidade são imprescritíveis.

64. Valle, Vanice Lírio; Menezes, Luciana, op. cit.

65. What is transitional justice? ICTJ - International Center of Transitional Justice. Disponível em: [www.ictj.org]. Acesso em: 23.03.2012. Ainda, sobre a posição crítica da instituição das comissões de verdade, vide nota 48 supra. E, a respeito das políticas adotadas no Brasil, ver Valle, Vanice Lírio; Menezes, Luciana, op. cit. e Tavares, André Ramos; Agra, Walber de Moura, op. cit.

66. Expressão utilizada por Flávia Piovesan. Cf. Piovesan, Flávia, op. cit., p. 69. 
Esta previsão, contudo, deve harmonizar-se com as demais disposições daquele pacto, mormente, com a legalidade que traz consigo o núcleo rígido da irretroatividade penal. Assim sendo, se a impunidade representa uma fratura no ideal da tutela do direito das gentes em razão da magnitude do bem jurídico violado, pior ainda seria a implosão de um dos pilares do rule of law que se manifestaria pela vulneração da legalidade.

Com muito mais razão, dentro da evolução sugerida por Teitel, o ideal de combate à impunidade da terceira fase da transitional justice genealogy não compromete a proposição de busca pela paz e harmonia nacional através de métodos alternativos à persecução penal. Assim sendo, a luta contra a impunidade das sérias violações ao direito humanitário não está na contramão da incorporação dos valores concebidos pelo Estado de Direito.

No que tange à anistia brasileira de 1979, por mais convincentes e racionais que se mostrem as críticas destinadas à mesma, esta efetivamente existiu na modalidade "de compromisso", com o objetivo de viabilizar pacificamente a transição para o regime democrático, além de outros motivos não declarados. Sobre o tema, Batista afirma que "podemos, se quisermos, lamentar que a anistia tenha sido tal como foi. Não devíamos ter perdoado a quem perdoamos, não devíamos; mas perdoamos. Agora é tarde".

Portanto, ao defender-se o Estado Democrático de Direito, o livre exercício da cidadania, a liberdade de expressão, para citar apenas alguns dos direitos pelos quais tanto sangue foi derramado, não é possível sustentar um processo penal em desconformidade com os princípios consagrados pela Carta de 1988.

Afinal, se a omissão não é justiça, o excesso muito menos pode ser considerado como tal. ${ }^{67}$ Com muito mais razão, a punição não pode ser objeto de retórica política, muito menos resultado de discursos emotivos, uma vez que a justiça de transição não apresenta a persecução penal como único e exclusivo mecanismo de reconciliação e restauração da paz.

\section{REFERÊNCIAS}

Ambus, Kai. O marco jurídico da justiça de transição. In: ; ZILLI, Marcos; Moura, Maria Thereza Rocha de Assis; Monteconrado, Fabíola Girão. Anistia, justiça e impunidade: reflexões sobre a justiça de transição no Brasil. Belo Horizonte: Fórum, 2010.

ARENDT, Hannah. Eichmann em Jerusalém. Um relato sobre a banalidade do mal. Trad. José Rubens Siqueira São Paulo: Cia. das Letras, 1999.

67. Cf. Zilli, Marcos, op. cit., p. 115. 
Arthur, Paige. How "transitions" reshaped human rights: a conceptual history of transitional justice. Human Rights Quarterly 31. Maryland: Johns Hopkins University Press, 2009.

Batista, Nilo. Aspectos jurídico-penais da anistia. Revista de Direito Penal. n. 26. Rio de Janeiro: Forense/Instituto de Ciências Penais do Rio de Janeiro, jul.-dez. 1979. Disponível em: [www.fragoso.com.br/eng/arq_pdf/direito_penal/conteudos/RDP26.pdf]. Acesso em: 29.05.2012.

. Introdução crítica ao direito penal. Rio de Janeiro: Revan, 2003.

. Justiça de transição no Brasil - Direito, responsabilização e verdade. In: Dimitri, Demoulis; Martins, Antonio; Swensson Junior, Lauro Joppert (orgs.). São Paulo: Saraiva, 2010.

Brasil. Decreto 4.388, de 25.09.2002. Promulga o Estatuto de Roma do Tribunal Penal Internacional. DOU 26.09.2002. Disponível em: [www.planalto.gov. br/ccivil_03/decreto/2002/D4388.htm].

Lei 6.683, de 21.08.1979. Concede a anistia e dá providências. DOU 28.08.1979. Disponível em: [www.planalto.gov.br/ccivil_03/Leis/L6683. htm]. Acesso em: 28.05.2012.

Secretaria Especial dos Direitos Humanos. Comissão Especial sobre Mortos e Desaparecidos Políticos, 2007. Disponível em: [http://portal. mj.gov.br/sedh/biblioteca/livro_direito_memoria_verdade/livro_direito_ memoria_verdade_sem_a_marca.pdf]. Acesso em 25.05.2012.

.STF. Rel. Min. Eros Grau. Disponível em: [www.stf.jus.br/arquivo/cms/ noticiaNoticiaStf/anexo/ADPF153.pdf]. Acesso em: 29.05.2012.

Carvalho, Salo. Antimanual de criminologia. Rio de Janeiro: Lumen Juris, 2011.

Cunha, Paulo Ribeiro. Militares e anistia no Brasil: um dueto desarmônico. In: Teles, Edson; Safatle, Vladimir. O que resta da ditadura. São Paulo: Boitempo, 2009. Coleção Estado de Sítio.

Dimoulis, Dimitri. Justiça de transição e função anistiante no Brasil. Hiposiações indevidas e caminhos de responsabilização. In: Dimitri, Demoulis; Martins, Antonio; Swensson Junior, Lauro Joppert (orgs.). Justiça de transição no Brasil - Direito, responsabilização e verdade. São Paulo: Saraiva, 2010.

ÉBOLI, Evandro. Deputados criam comissão da verdade paralela: Insatisfeitos com a lentidão do governo, parlamentares começam a ouvir testemunhas de crimes cometidos durante a ditadura militar. O Globo, Cad. 1, Rio de janeiro, 04.04.2012, p. 11.

Fausto, Boris. História concisa do Brasil. São Paulo: Edusp, 2009.

Foucault, Michel. A ordem do discurso. Aula inaugural do College de France, pronunciada em 2 de dezembro de 1970. 21. ed. São Paulo: Loyola, 2011.

. Vigiar e punir. Petrópolis: Vozes, 2000.

GóEs, Bruno. Tumulto no encontro de atos pró e contra golpe. Manifestantes cobram punição para crimes da ditadura e entram em conflito com militares que comemoravam a data. O Globo, Cad. O País, Rio de Janeiro, 30.03.2012, p. 13. 
Hobsbawn, Eric. Era dos extremos. O breve século XX - 1914-1991. Trad. Marcos Santa Rita, revisão técnica Maria Célia Paoli. 2. ed., 44. reimp. São Paulo: Cia. das Letras, 1995.

Japiassú, Carlos Eduardo Adriano. O Tribunal Penal Internacional. A internacionalização do direito penal. Rio de Janeiro: Lumen Juris, 2004.

Jiunn-Rong, Yeh; Wen-Chen, Chang. The changing landscape of modern constitucionalism: transitional perspective. National Taiwan University Law Review. vol. 4. n. 1. p. 145-183. March 31. 2009. Disponível em: [http:ssrn. com/abstract=1482863]. Acesso em: 10.05.2012.

Kelsen, Hans. Will the judgement in Nuremberg Trial constitute a precedent international Law? The International Law Quaterly. vol. 1. n. 2. Cambrige University Press, Summer 1947.

Langa, Pius. Transformative constitucionlism. Stellenbosch University, Prestige Lecture, oct. 2006. Online. Disponível em: [http://sun025.sun.ac.za/portal/ page/portal/law/index.afrikaans/nuus/2006/Pius\%20Langa\%20Speech.pdf]. Acesso em: 01.04.2012.

Mello, Osvaldo Aranha Bandeira. Imprescritibilidade dos crimes de tortura. In: SoAres, Inês Virgínia Prado; KISHI, Sandra Akemi Shimada (coords.). Memória e verdade: a justiça de transição no Estado Democrático brasileiro. Belo Horizonte: Fórum, 2009.

Melossi, Dario; Pavarini, Massimo. Cárcere e fábrica. As origens do sistema penitenciário (séculos XVI e XIX). Rio de Janeiro: Revan, 2006.

Ministério Público Federal traça estratégia para investigar ditadura. Disponível em: [http://oglobo.globo.com/pais/ministerio-publico-federal-traca-estrategia-para-investigar-ditadura-4264597]. Acesso em: 28.05.2012.

Neves, Marcelo. A força simbólica dos direitos humanos. Revista Eletrônica de Direito do Estado. n. 4. Salvador: Instituto de Direito Público da Bahia, out.-dez. 2005. Disponível em: [www.direitodoestado.com.br]. Acesso em: 29.05.2012.

OEA. Corte IDH. Caso Gomes Lund y otros (Guerrilha do Araguaia) vs. Brasil. Sentencia de 24.11.2010. Versão em Português Série C. n. 219. Disponível: [www.corteidh.or.cr/docs/casos/articulos/seriec_219_por.pdf]. Acesso em: 01.05.2012.

Ohlin, Jens David. On the very idea of transitional justice. The Whitehead Journal of Diplomacy and International Relations. vol. 8. n. 1. p. 51-68. 2007. Social Science Research Network. Disponível em: [http://papers.ssrn.com/ sol3/DisplayAbstractSearch.cfm]. Acesso em: 20.11.2011.

ONU. Resolução 771, de 13.08.1992, do Tribunal Penal Internacional para a antiga Iugoslávia. Disponível em: [http://daccess-dds-ny.un.org/doc/UNDOC/GEN/N92/379/72/IMG/N9237972.pdf?OpenElement]. Acesso em: 24.05.2012. 
Resolução 955, de 08.11.1994, do Tribunal Penal Internacional para Ruanda. Disponível em: [http://daccess-dds-ny.un.org/doc/UNDOC/GEN/ N95/140/97/PDF/N9514097.pdf?OpenElement]. Acesso em: 24.05.2012.

Piovesan, Flávia. Direitos humanos e o direito constitucional internacional. 7. ed. São Paulo: Saraiva, 2006.

SHIRER, William L. Ascensão e queda do Terceiro Reich. Rio de Janeiro: Civilização Brasileira, 1962. vol. I.

SOARES, Inês Virgínia Prado. Memória democrática e desaparecidos políticos. In: ; KısHi, Sandra Akemi Shimada (coords.). Memória e verdade: a justiça de transição no Estado Democrático brasileiro. Belo Horizonte: Fórum, 2009. p. $317-340$.

SWEnsson Junior, Lauro Joppert. Punição para os crimes da ditadura militar. Contornos do debate. In: Dimitri, Demoulis; Martins, Antonio; Swensson JuNIoR, Lauro Joppert (orgs.). Justiça de transição no Brasil - Direito, responsabilização e verdade. São Paulo: Saraiva, 2010.

Tavares, André Ramos; Agra, Walber de Moura. Justiça reparadora no Brasil. In: SOARES, Inês Virgínia Prado; KisHi, Sandra Akemi Shimada (coords.). Memória e verdade: a justiça de transição no Estado Democrático brasileiro. Belo Horizonte: Fórum, 2009.

Teitel, Ruti. The law and politics of contemporary transitional justice. Social Science Research Network. New York Law School's website. Disponível em: [http://ssrn.com/abstract=943069]. Acesso em: 20.11.2011.

Teitel, Ruti. Transitional justice genealogy. Symposium Human Rights in Transition. 16 Harvard Human Rights Journal. p. 69-94. 2003.

Uribe, Gustavo; Bruno, Cássio. "Não tem dois lados, o outro lado foi assassinado". Integrantes da Comissão da Verdade já se dividem sobre o foco da investigação, centrada nos crimes de agentes públicos. O Globo, Cad. 1, Rio de Janeiro, 15.05.2012, p. 11.

Valle, Vanice Lírio; Menezes, Luciana. Justiça de transição e direitos humanos: dilemas na afirmação de um direito a esquecer. A \& C Revista de Direito Administrativo e Constitucional. n. 48. ano 12. Belo Horizonte: Fórum, abr.-jun. 2012.

What is transitional justice? ICTJ - International Center of Transitional Justice. Disponível em: [www.ictj.org]. Acesso em: 23.03.2012.

Zilli, Marcos. O último tango? In: SoAres, Inês Virgínia Prado; Kishi, Sandra Akemi Shimada (coords.). Memória e verdade: a justiça de transição no Estado Democrático brasileiro. Belo Horizonte: Fórum, 2009. 


\section{Pesquisas do Editorial}

\section{Veja também Doutrina}

- A anistia e os crimes contra a humanidade, de Edson Luis de Almeida - RBCCrim 55/315;

- A declaração de inconvencionalidade da lei de anistia brasileira pela Corte Interamericana de Direitos Humanos no Caso Gomes Lund e outros vs. Brasil (Guerrilha do Araguaia), de Deo Campos Dutra e Sílvia Maria Da Silveira Loureiro - RT 920/183;

- Direito à memória e reparação: da inclusão jurídica das pessoas perseguidas e torturadas na ditadura militar brasileira, de Irene Patrícia Nohara - RDCl 67/125;

- 0 esclarecimento da verdade sobre graves violações dos direitos humanos, de Jan-Michael Simon - RBCCrim 92/403; e

- 0 regime militar e a justiça de transição no Brasil. Para onde caminhar?, de Marcos Zilli - RBCCrim 93/61. 